\title{
Criança vítima de violência sexual Recortes de um caso atendido na Abordagem Centrada na Pessoa
}

\section{Child sexual violence victim: a case study according to the person centered approach}

\author{
Juliana Leila Campos*
}

Resumo

$\mathrm{O}$ abuso sexual infantil integra o complexo fenômeno da violência. $\mathrm{O}$ serviço de proteção social, PAEFI, é destinado a acolher e assistir as famílias que tiveram suas crianças acometidas por esta violência, embora não haja diretrizes ou normativas específicas para o profissional de psicologia atuar nestes casos. O presente estudo traz recortes de um caso de uma criança vítima de violência sexual atendida pelo Serviço de Proteção e Atendimento Especializado a Famílias e Indivíduos; descreve e discute um modo de atuação profissional em Psicologia, segundo os pressupostos da Abordagem Centrada na Pessoa. Conclui-se sobre a importância de um modo de atuação possível em ambiente institucional, além do consultório; sugere a proposta de intervenção que acredita genuinamente na capacidade de crescimento pessoal da criança vitimada, com possibilidades de tendência atualizante, na medida em que o terapeuta atue como facilitador.

Palavras-chave: Abuso Sexual; violência infantil; Abordagem Centrada na Pessoa; PAEFI.

* Psicóloga, graduada pela Universidade Federal de Minas Gerais, Analista de Políticas Públicas da Prefeitura Municipal de Belo Horizonte, Especialista em Intervenção Psicossocial no Contexto das Políticas Públicas e Especialista em Psicoterapia Existencial Fenomenológica. 


\section{Abstract}

Child sexual abuse is part of the complex phenomenon of violence. The social protection service, PAEFI, aims to accommodate and assist families whose children have been affected by this violence, although there are no specific guidelines or regulations for the psychology professional to act in these cases. The present study brings out a case of a child victim of sexual violence attended by the Specialized Service of Protection and Care for Families and Individuals; Describes and discusses a mode of professional practice in Psychology, according to the presuppositions of the Person Centered Approach. It concludes on the importance of a possible way of acting in institutional environment, besides the office; suggests an intervention proposal that genuinely believes in the personal growth capacity of the victimized child, with possibilities of updating tendency, insofar as the therapist acts as a facilitator.

Keywords: Sexual abuse; Violence against children; Person Centered Approach; PAEFI.

\section{Introdução}

A violência sexual contra criança caracteriza-se pela situação em que a mesma é usada para a satisfação sexual de um adulto ou adolescente mais velho, (responsável por ela ou que possua algum vínculo familiar ou de relacionamento, atual ou anterior). Esse tipo de violência inclui o abuso sexual, exploração sexual, voyeurismo, pornografia, exibicionismo, até o ato sexual, com ou sem penetração, sendo a violência sempre presumida em menores de 14 anos (ABRAPIA, 1997). Já o abuso sexual, mais especificamente, consiste em submeter uma pessoa a si, pelo uso do poder, para obter gratificação sexual. Conforme, Santos e Alves (2010), o abuso pode envolver o emprego, uso, persuasão, indução, coerção ou qualquer experiência sexual que interfira na saúde do indivíduo incluindo componentes físicos, verbais e emocionais.

$\mathrm{O}$ abuso sexual tem tido sua gravidade acentuada por se tratar de um fenômeno complexo, difícil de ser enfrentado, e por se tratar de uma forma de violência endêmica; tanto que Briere e Elliott (2003) mencionam estudos realizados em diversas partes do mundo que apontam que entre 7 e $36 \%$ das meninas e entre 3 a $29 \%$ dos meninos já sofreram abuso sexual. Florentino (2015) num levantamento 
sobre pesquisas realizadas sobre os impactos da violência sexual sobre as crianças e adolescentes, concluiu que devido à brutalidade em que ocorre o abuso sexual infantil, em geral associado a outros tipos de violência, como: física e psicológica, é quase que certo que a criança desenvolva diferentes consequências de natureza psicológica ou psiquiátrica; entretanto, não é possível generalizar os efeitos do abuso sexual, uma vez que a gravidade e a extensão das consequências dependem de particularidades da experiência de cada vítima.

Diante desse contexto alarmante surge a indagação: como olhar para a criança vítima de abuso sexual sem vitimá-la mais que as circunstâncias já o fizeram? Esse desafio parece grande, contudo ele é ainda maior quando o lugar de onde esta criança é vista é um serviço público da assistência social, mais especificamente o Serviço de Proteção e Atendimento Especializado à Família e Indivíduo (PAEFI). Esse serviço, conforme Resolução CNAS no 109/2009 (BRASIL, 2009) tem como um dos objetivos o fortalecimento de vínculo e a superação de situações de violação de direito.

Dessa forma, o profissional de psicologia inserido no serviço de proteção social deve dirigir seu olhar para a criança vitima de violência sexual, considerando os vários aspectos e contextos que influenciam o seu desenvolvimento: físico, cognitivo, emocional, familiar, social. O desafio posto a este profissional inserido no serviço público de proteção social voltado para o acompanhamento de família e de pessoas vítimas de violência, aqui mais especificamente a violência sexual, emerge da necessidade de olhar com os olhos do outro; e o que Rogers (1951/ 1992) chamou de empatia; termo que C. Rogers chamou de empatia ou compreensão empática, como uma das condições facilitadoras no processo terapêutico e em toda sua teoria.

\section{Serviço de proteção especializado à família} e indivíduo - PAEFI e o Atendimento Psicossocial

O PAEFI é um serviço socioassistencial, ofertado no Centro de Referência Especializada da Assistência Social (CREAS), que deve, segundo a Tipificação Nacional dos Serviços Sócio-assistenciais (BRASIL, 2009), prestar "apoio, orientação e acompanhamento a 
famílias com um ou mais de seus membros em situação de ameaça ou violação de direitos". Constitui-se como serviço público destinado a acompanhar famílias e indivíduos que vivenciam situações de violência física, psicológica, negligência, dentre outras formas de violação de direitos.

A atuação do psicólogo enquanto trabalhador pertencente à política de Assistência Social está vinculada ao objetivo básico de promover o fortalecimento dos usuários na qualidade de sujeitos de direitos, bem como fomentar a consolidação dessa política pública. Dessa forma, o exercício do psicólogo deve abarcar o compromisso com a valorização de conteúdos salubres inerentes ou presentes nos indivíduos, nas famílias e na comunidade. As articulações entre a prática psicológica com o compromisso social têm contribuído, portanto, para o resgate dos vínculos do usuário com a Assistência Social (CRESS; CFP, 2007).

Diante disso, o atendimento psicossocial realizado pelo profissional de psicologia deve, de forma sucinta, priorizar procedimentos técnicos voltados para ações psicossocioeducativas, que visem a proteção dos indivíduos, envolvendo estes em ações que propiciem o fortalecimento da sua autonomia. Deve buscar, também, o fortalecimento da convivência familiar e comunitária de forma digna, visando assim a redução dos impactos das vulnerabilidades sociais e o desenvolvimento de meios de enfrentamento da situação de violação de direitos.

Importante frisar que o acompanhamento das famílias nos serviços da assistência social, sobretudo no âmbito do PAEFI, se dá de forma ativa e participativa. Por conseguinte os membros da família são chamados a construir conjuntamente com o técnico de referência, aqui o psicólogo, ações e estratégias de enfrentamento da violação a qual se encontram submetidos. Importante destacar, ainda, que o profissional de psicologia, nos atendimentos realizados no PAEFI, tem o desafio de estimular e desempenhar estratégias e propostas de intervenção que pretendam ter efeitos terapêuticos, sem, contudo, tornarem-se psicoterapêuticos, visto a forma de intervenção e os objetivos (CRESS; CFP, 2007).

Tratando mais especificamente do atendimento feito às crianças vitimas de violência sexual, de acordo com as orientações trazidas 
pelo CFP (2009) o atendimento às estas crianças deve se voltar para a redução de danos sofridos por elas. Desta forma, deve-se buscar estimular e desenvolver nessas crianças mudanças de condições subjetivas que favoreçam em certa medida a instauração ou a manutenção da situação abusiva.

Assim é imprescindível que o profissional priorize um olhar para cada criança, vitima da violência sexual, reconhecendo sua particularidade e singularidade, considerando sua subjetividade, deslocando-a da cena que a coloca como mais uma vitima em um universo de iguais. Estas são medidas fundamentais na tentativa de compreender e auxiliar a criança a movimentar-se em busca da sua autonomia e auto-determinação.

\section{Considerações gerais sobre a criança segundo concepções de Carl Rogers}

O desenvolvimento humano é um processo multidirecional e multidimensional em que todas as fases da vida há perdas, ganhos e manutenções. Fadman e Frager (1986) entenderam que na infância o indivíduo vivencia uma série de dificuldades e obstáculos que são aspectos normais do desenvolvimento. Assim, para superar os obstáculos que o crescimento impõe, a criança é levada a aprender um conjunto de regras de convivência social que futuramente podem levá-la a uma inibição da sua real personalidade (FADMAN; FRAGER, 1986).

Conforme Rogers (1961/1987), as crianças pequenas tendem a possuir um alto grau de congruência, pois elas demonstram ter uma maior sincronia entre o que sentem e como se expressam. Os sentimentos e as emoções das crianças são manifestações intensas que podem variar severamente de um estado ao outro, isto é, quando uma criança sente amor ou raiva, em questão de minutos, ela substitui um estado emocional por outro com muita facilidade. Essa simplicidade para expressar os sentimentos possibilita às crianças dar vazão à descarga emocional das suas experiências, tanto presentes como passadas, evitando assim uma sobrecarga emocional.

Segundo Rogers (1951/1992) o ser humano possui uma necessidade de consideração positiva, assim, embora as crianças apresentem 
um estado de congruência satisfatório entre as suas experiências e a capacidade de expressá-las, elas são seres altamente dependentes da aprovação do outro. O amor é tão fundamental na infância que as crianças não são dirigidas pelo caráter agradável ou não das suas experiências, mas sim pelo quanto de afeto e amor que esta experiência irá lhe custar.

Cabe ressaltar que a evolução saudável de uma personalidade na infância está intrinsecamente ligada ao contexto das relações afetivas das crianças e à intensidade com que estas se sintam amadas. Portanto, as crianças possuem uma necessidade essencial de ser aceita e respeitada dentro de suas peculiaridades, de sentirem-se assim, merecedoras do amor, do afeto, do respeito e da atenção das pessoas que lhes são caras.

Acreditar no potencial da criança é atitude perene que deve ser desempenhada por todo profissional que intente construir uma relação de ajuda e amparo com a mesma. Rogers (1939/1978) bem coloca isso ao dizer que "deve haver uma disposição para aceitar a criança como ela é (...) e dar-lhe liberdade para tentar soluções próprias para os seus problemas" (p. 247).

\section{Encontrar a criança na relação terapêutica e a compreensão empática no ałendimento}

Encontrar a criança, ir ao encontro dela, descobrir, deparar; são todos verbos que remetem a uma mesma concepção; estar com a criança em algum momento, em um dado espaço. Aqui este encontro acontece na hora do atendimento, seja ele clínico ou psicossocial, a concepção é a mesma. Não importa o objetivo do atendimento, nem tampouco o espaço em que ele aconteça; estar com a outra pessoa é se permitir vivenciar o momento do encontro na sua plenitude, é despojar-se do que é estrangeiro à relação e vivê-la sem limites doando-se e permitindo-se receber o que vem do outro indivíduo.

$\mathrm{O}$ encontro que ocorre entre o profissional e a criança em um espaço que se destina a ouvir esta criança com algum caráter terapêutico deve considerar fundamentalmente acreditar na criança como sendo a principal responsável por seu processo de mudança. Assim, este encontro deve alicerçar-se na hipótese central da ACP 
que diz da capacidade do indivíduo para o crescimento e autodirecionamento (ROGERS, 1951/1992)

Receber a criança em sua integralidade, proporcionar a ela um espaço de respeito, de escuta, de troca, um espaço de silêncio, quando este for o desejo da criança, um espaço de acolhida, de compreensão. Espaço este onde "a criança se sinta segura o bastante para relaxar suas defesas por tempo suficiente e ver como é a sensação de atuar sem elas." (ROGERS, 1951, p. 276). Receber a criança despida de qualquer diagnóstico, de qualquer demanda, previamente determinada, recebê-la exatamente como ela se apresenta e, sobretudo, aceitá-la "exatamente como ela é naquele momento, e não tentar moldá-la em alguma forma socialmente aprovada" (ROGERS, 1951, p. 276).

É importante considerar que quando a criança chega para ser atendida, ela é sempre levada por outra pessoa, assim por mais que esta outra pessoa tenha falado para a criança sobre o atendimento, toda aquela experiência é nova para a mesma. Logo, é imprescindível em um atendimento que se proponha ser centrado na criança, o esclarecimento dos motivos pelos quais ela está naquele espaço.

Após este esclarecimento, o tempo e o ritmo do acompanhamento serão determinados pela própria criança. Por mais que o atendimento não tenha um caráter clínico, é importante que o profissional aceite o ritmo escolhido pela criança e a auxilie na expressão de suas vivências, limitando-se a auxiliá-la na travessia da sua experiência pessoal de acordo com a sua disponibilidade para tal.

A compreensão empática no atendimento feito com crianças tende a funcionar como um agente facilitador do processo de crescimento das mesmas, bem como de superação de alguma situação desagradável na qual a criança se encontra. Assim, é preciso que haja uma disponibilidade pessoal do profissional para receber a criança, é essencial que haja espaço para estar com esta criança e aceitá-la em sua integralidade e unicidade. Deixar a criança livre é permitir que a mesma se manifeste, e manifestar-se é permitir o contato.

Ante esse contexto de violência em que está inserida a criança, procuramos olhar para ela, permitir que ela fale do seu modo, 
do seu lugar, da sua vida, olhar para ela com os olhos de quem desconhece. Permitimos conhecer esta criança a partir do que ela traz de si e não a partir do que é trazido sobre ela. A violência agride, machuca, fere, deixa marcas, mas acreditar no potencial de crescimento desta criança e favorecer este crescimento, por meio de condições que promovam o desenvolvimento da sua autonomia é o que deve guiar o trabalho com vítimas de abuso sexual.

Assim sendo, o presente estudo apresenta como objetivo um relato de uma experiência de atuação profissional em psicologia de abordagem centrada na pessoa, de uma criança com queixa de abuso sexual.

\section{Método}

O presente trata-se de um estudo de caso descritivo, ou seja, um estudo que tem como finalidade a descrição de uma intervenção em seu contexto de vida de real (YIN, 2001). Por se tratar de um estudo de caso único, este trabalho buscará ter o cuidado com as generalizações que, por ventura, possam ser feitas; além disso, por se tratar de um estudo de caso, conforme Yin (2001), é possível que ao longo do mesmo não se encontre a situação que se pensava estudar, podendo, dessa forma, ter ou não a adesão à teoria inicialmente proposta

Tendo em vista que o objetivo do PAEFI é contribuir para a superação da situação de violação que levou a família ao Serviço, freqüentemente são realizados nos acompanhamentos sóciofamiliares, bem como atendimentos individuais e ao grupo familiar; além de visitas domiciliares. Os contatos e discussões de caso também são feitos com os técnicos da rede sócio-assistencial e demais orientações e encaminhamentos. Tais medidas intentam promover o desenvolvimento da autonomia da família, para a promoção e/ou aumento de sua função de proteção. O trabalho é então construído com as famílias, buscando sempre minimizar e mitigar os impactos da violação de direito, bem como evitar a sua recorrência.

Posto isso, pretende-se descrever uma experiência de atendimento psicológico baseado na abordagem "centrada na pessoa", de uma criança vítima de abuso sexual, fora do contexto clínico de consultório, ou seja, numa instituição (PAEFI) - Serviço Sócio 
-assistencial e que se assenta no contexto das políticas públicas de proteção ao indivíduo.

Todavia, cabe ressaltar que a descrição dos atendimentos será baseada nos relatos dos atendimentos presentes nos relatórios do prontuário da família, uma vez que a possibilidade de se realizar este estudo se deu no decorrer do acompanhamento sóciofamiliar, logo os mesmos não foram gravados.

Procedimento - a atenção psicológica em questão foi realizada no Serviço de Atendimento Especializado à Família e ao Indivíduo - PAEFI, com uma criança do sexo masculino de seis anos, aqui chamada de Miguel. A fim de manter o anonimato dos envolvidos os genitores serão chamados de Sueli e Luiz. O núcleo familiar de Miguel foi encaminhado para este serviço por determinação legal do Conselho Tutelar. Em função da demanda do PAEFI, foram realizados apenas dois atendimentos individuais mensais com a criança e um atendimento mensal à genitora.

Dessa forma, o acompanhamento durou aproximadamente sete meses, totalizando treze atendimentos à criança. Os atendimentos tinham duração de cerca de cinqüenta minutos e ocorriam em salas individuais disponibilizadas pelo equipamento público. Cabe ressaltar que a sala de atendimento não disponibilizava muitos recursos materiais para o atendimento à criança, dessa forma, as atividades lúdicas eram limitadas, ainda assim eram disponibilizados folhas de papel, lápis de cor e giz de cera.

Por fim, é importante frisar que a utilização das falas foi realizada com a devida autorização dos responsáveis.

\section{O relato do caso}

\section{Contextualizando o caso Miguel}

Em princípio, a família era composta por Miguel (criança), Sueli (mãe) e Luiz (pai). O casal se revezava nos cuidados com a criança, enquanto Sra.Sueli cuidava de Miguel durante o dia, Sra.Luiz ficava com o filho à noite. Sra.Sueli relatou nunca ter percebido nenhuma mudança de comportamento em Miguel; todavia, certo dia ela se deparou com o genitor manipulando o órgão sexual da criança. È interessante salientar que nesta época a criança tinha aproximada- 
mente 3 anos. Diante deste fato, a genitora se mudou com a criança para outra cidade, mas não realizou nenhum tipo de denúncia, pois relatou que a culpa que carregava pela violência que a criança havia sido acometida era maior que o desejo de punir o responsável.

Após mais de um ano sem contato com o genitor, Sra.Sueli voltou a permitir que Sra. Luiz (ex marido) se reaproximasse de sua da família que agora, era formada por ela, Miguel e outra criança, fruto de outra união conjugal de Sueli. Assim, Sra.Luiz passou a freqüentar a casa de Sueli reiteradamente, pois além de ir visitar o filho, o genitor estava cuidando de obras que estavam sendo feitas na casa da Sra. Sueli.

O genitor ia à casa para cuidar das reformas, enquanto a mãe de Miguel estava trabalhando e nestes momentos, de acordo com relato da própria Sueli, ele voltou a abusar do filho. Neste período Miguel já era uma criança de 4 anos que novamente voltou a ser violentada sexualmente por seu pai.

A genitora não constatou o fato como anteriormente, mas percebeu uma mudança no comportamento da criança, que se tornara agressiva, desconfiada e chorava a todo o momento sem causas aparentes. Apesar dessas mudanças, Sra.Sueli só se deparou com a situação do abuso após Miguel lhe dizer que quando ficava com pai, este "mexia" (sic) em seu "pintinho" (sic); foi então que a genitora suspeitou que o filho estava sendo abusado novamente. Na ocasião ela levou o filho a uma unidade de saúde que acionou o Conselho Tutelar e denunciou o genitor, o qual, desde a denúncia não voltou a ver o filho. Em razão da notificação do Conselho Tutelar a família foi encaminhada para o Serviço de Atendimento Especializado à Família e Indivíduo - PAEFI.

Sobre Miguel, a genitora informou no início do acompanhamento, que se tratava de uma criança sensível, que estava muito apegada a ela, tinha medo das pessoas, chorava com frequência e não gostava de brincar com ouras crianças. Sra. Sueli informou ainda, que Miguel resgatava constantemente as cenas do abuso referindo-se da seguinte forma: "lembra mamãe quando meu pai fazia aquilo comigo?"(sic). Conforme a genitora, Miguel falava do abuso e chorava, sempre que queria conseguir algo, e ela, conseqüentemente acabava cedendo aos desejos da criança. 


\section{O acompanhamento a Miguel}

Abaixo seguem recortes de atendimentos considerados mais relevantes para fins desta produção. As passagens foram organizadas em ordem cronológica dos atendimentos ocorridos.

Depois da acolhida às demandas trazidas pela Sueli e, sobretudo uma acolhida a angústia da mesma, o serviço realizou um trabalho de orientação à genitora visando uma maior efetividade no acompanhamento a Miguel. Sueli foi orientada a não vitimá-lo mais do que as circunstâncias já o tinham feito. Assim a orientação dada foi no sentido de que a Sueli não tratasse a criança como vítima e a colocasse no lugar de "coitada"; ao contrário ela deveria incentivar e reforçar comportamentos naturais e freqüentes em crianças da idade do Miguel. A genitora foi orientada, também, a conversar com a criança sempre que esta retomasse o abuso, enfatizando que se tratava de um episódio que já havia passado e que não voltaria acontecer. Foi colocada a importância de proporcionar um ambiente em que Miguel se sentisse seguro e protegido.

Assim, o trabalho que a profissional de psicologia procurou desenvolver com a criança foi no sentido de proporcionar-lhe condições para o seu crescimento, auto-realização, bem como atenuação e possível superação da violência vivenciada. Foi enfatizado com a genitora que ao falar em superação, não se tratava de imaginar que a criança iria esquecer o que viveu e tampouco ignorar o passado. $\mathrm{O}$ sentido dado à palavra superação referiu-se a um atravessamento daquela situação de uma forma menos angustiante possível. Tratava-se, portanto de proporcionar a Miguel condições favoráveis para que o mesmo tivesse condições de atribuir novos significados à sua experiência, e que estes significados os encaminhassem para um crescimento pessoal.

A acolhida feita a Miguel, logo no inicio do acompanhamento, foi muito importante para a relação e criação de vínculo entre ele a psicóloga - técnica do serviço. Houve por parte desta profissional uma preocupação em demonstrar consideração e respeito para com a criança; houve uma tentativa de aproximação sensível entre a profissional e a criança, que embora tímida, permitiu-se envolver pelo clima de acolhida naquele espaço. Assim, o rapport fora estabelecido da seguinte forma: 
A psicóloga perguntou a Miguel se ele sabia por que estava naquele serviço, e ele abanou a cabeça em sinal negativo. A profissional esclareceu-lhe então que estava ali para poder conversar, e que o fizesse quando tivesse vontade, assim como desenhar, brincar ou ficar em silêncio, se assim quisesse. Esclareceu ainda que aquele momento era dele e tudo que acontecesse ali dentro seria um segredo entre ele e ela, mas que se ele quisesse poderia contar para sua mãe. Miguel permaneceu sentado à mesa, olhando os papéis que estavam distribuídos sobre a mesma, mas não mexeu em nenhum, esboçando apenas uma cálida fisionomia que tomara o lugar da expressão tímida...

Neste ponto a terapeuta manteve a orientação da Terapia Centrada na Pessoa, ao entender conforme explica Mattar (2010) que ao seguir as orientações de Virginia Axiline o terapeuta mantém uma atitude de modo a não revelar as confidências da criança aos pais, professores ou quem quer que seja que pergunte sobre o que ela. Entende, pois, Axline (1947) que esta hora é da criança, e o que ela faz ou expressa é estritamente confidencial.

Durante os atendimentos que se sucederam as brincadeiras eram escolhidas e determinadas por Miguel; era ele quem decidia o que iria fazer; desenhar, brincar ou apenas conversar com a psicóloga, a escolha era sempre dele.

Miguel chegou ao atendimento, foi até o armário de brinquedos e disse ${ }^{1}$ :

M. hoje não vou desenhar, e sim brincar...

Sentou-se à mesa, distribuiu alguns brinquedos e começou a brincar. Durante a brincadeira Miguel ficou em silêncio por um longo tempo, até interromper o silêncio e dizer:

M. minha irmãzinha está doente, eu estou ajudando mamãe a cuidar dela.

$\boldsymbol{P}$. parece que você gosta de ajudar a cuidar da sua irmã.

M. a gente tem que cuidar porque ela é pequena.

$\boldsymbol{P}$. então você acha que as pessoas pequenas precisam ser cuidadas.

M. sim, os grandes precisam cuidar dos pequenos.

M - Miguel

P - Técnica de Psicologia do PAEFI 
P. entendi que você acha que as pessoas adultas devem cuidar das crianças. M. é...

Miguel deixou os brinquedos, pegou as folhas de papel e começou a desenhar. Enquanto desenhava ele perguntou:

M. Você chora?

P. Sim Miguel, eu choro quando sinto vontade e você?

M. eu choro quando minha irmãzinha está passando mal e chorando [...] os pequenos não podem chorar...

P. Então você acha que as crianças não podem chorar?

M. podem... mas só quando estão doente. Os grandes não podem fazer as criancinhas chorar...

$P$. entendi que você acha que os adultos não devem fazer as crianças chorar. M. Não... não devem. Eu choro quando a minha mãe briga comigo [...] quando meu pai me "ameaçava" também.

$\boldsymbol{P}$. Então hoje você chora quando sua mãe briga com você, e antes quando morava com seu pai você chorava quando ele te "ameaçava".

M. aham... cadê a minha mãe?

Miguel começa a rodar com o carrinho na sala e não fala mais.

Este tipo de abordagem do profissional possibilita que a criança se expresse livremente. Assim, conforme preconizado por Axline (1947), o profissional deve evitar dirigir as ações ou conversas da criança, esta deve sentir-se livre em suas escolhas, assim como Miguel demonstrou se sentir.

Miguel sempre demonstrou um interesse especial pelos desenhos, deste modo normalmente ele chegava ao atendimento, sentava-se à mesa e começava a desenhar. Por vezes era percebido que ele ficava esperando a psicóloga lhe dizer algo ou lhe dar algum comando, contudo como esta espera não era correspondida, e então ele quebrava o silêncio trazendo algo da sua experiência naquele momento. Dessa forma, por meio da liberdade que a psicóloga proporcionava à criança, os atendimentos eram conduzidos conforme as escolhas de Miguel.

Em dado atendimento, ao chegar, Miguel sentou-se à mesa e começou a desenhar. A psicóloga disse-lhe que se ele quisesse poderia brincar com os brinquedos disponíveis na sala, contudo ele só se interessou em desenhar. 
Após terminar o desenho, ele olhou para a psicóloga e falou:

M. [...] sabe quem são estes? Apontando para os desenhos de figuras humanas.

$P$. não sei. Quem são estes?

M. eu e minha mãe uai.

Enquanto respondia ele ficava olhando para o desenho.

M. você não vai perguntar nada não.

$\boldsymbol{P}$. Você quer que eu pergunte algo?

M. não. Todo mundo pergunta.

Miguel pegou alguns lápis de cor, começou a colorir os desenhos.

M. lá em casa só mora eu, minha mãe e minha irmãzinha...

Já ao final do atendimento Miguel pegou uma nova folha e desenhou, conforme ele próprio nomeou uma casa, um pássaro e sua mãe. Suas últimas palavras neste atendimento referindo-se ao segundo desenho foram;

M. todos juntos.

Quando a criança perguntava à psicóloga se esta não iria lhe dizer ou pedir nada, é possível inferir que nos demais espaços e/ou relações ele estava sendo constantemente chamado a fazer ou falar sobre determinado assunto, não lhe era reservada a liberdade de escolher o que e quando falar. Contudo, no atendimento não houve esta demanda por parte da psicóloga. A liberdade, a consideração positiva incondicional e a acolhida, presentes nos primeiros atendimentos foram fundamentais para o estabelecimento da empatia entre a criança e a profissional. Assim, conforme Rogers (1957/2008) a primeira condição necessária para que a pessoa vivencie uma mudança construtiva de sua personalidade, foi estabelecida, trata-se do contato psicológico entre duas pessoas, compreendida em Rogers (1961/1987) como congruência, situação em que o profissional de psicologia age sem máscaras, estabelecendo uma presença significativa e calorosa durante o atendimento.

Além do contato psicológico já estabelecido a acolhida da psicóloga para com Miguel foi fundamental para proporcionar a ele condições de se sentir livre para se expressar e para diminuir sua expectativa em relação ao que a profissional poderia esperar 
dele. Esta situação caracterizaria a aceitação positiva incondicional, que para Rogers (1961/1987) é outra condição facilitadora do processo de mudança terapêutica da personalidade. A aceitação positiva incondicional é uma forma de considerar o outro "como uma pessoa separada, digna de respeito por um mérito que lhe é próprio. É uma confiança básica - uma crença de que esta outra pessoa é, de alguma maneira fundamental, digna de confiança" (ROGERS, 1974/1977, p.149). Assim, esta condição contribuiu, dentre outras, para que a expressão de sentimento de Miguel fluísse de forma gradativa e crescente ao longo dos atendimentos.

Miguel chegou ao atendimento bem animado. Ele sentou-se à sala de atendimento e começou a desenhar. Após, falou que sua irmãzinha estava passando muito mal.

Miguel começou a desenhar e a falar a respeito sua família. Falou sobre a avó paterna e sobre uma prima que, segundo ele, sentia muita saudade. Neste momento falou a respeito do pai e, disse que havia muito tempo que não o via e que havia falado com ele apenas ao telefone. Ao falar sobre sua prima, Miguel disse:

M. antes eu brincava muito com ela.

$P$. Parece que você sente saudades de brincar com ela.

M. as vezes, porque era bom, mas era ruim, porque meu pai fazia aquelas coisas

$\boldsymbol{P}$. Entendi que você sente saudades da sua prima porque você gostava de brincar com ela, mas quando lembra das coisas que o seu pai fazia, então a saudade passa.

M. [...] pergunta a minha mãe o que papai fazia.

$\boldsymbol{P}$. vamos fazer assim, eu não vou perguntar nada a sua mãe. E quando você quiser me falar sobre as "coisas" que o seu pai fazia com você, você me conta, tá?

M. você gosta de conversar comigo.

P. Sim Miguel, eu gosto de conversar com você.

M. eu também.

Apesar de os atendimentos no Serviço de Atendimento Especializado à Família e Indivíduo acontecerem de forma espaçada era perceptível que a cada novo atendimento Miguel se sentia mais 
à vontade e mais adquiria autoconfiança para se apropriar tanto do espaço físico da sala de atendimento, quanto do próprio atendimento enquanto espaço de troca, de fala e de escuta. É possível inferir que esta apropriação do atendimento e o próprio sentimento de liberdade que Miguel experimentava estavam intimamente relacionados com, dentre outros fatores, a aceitação que ele encontrou naquele espaço. O princípio trazido por Axline (1947) em que a mesma discorre sobre importância do profissional aceitar a criança exatamente como ela é, parece ter sido de extrema importância para possibilitar e favorecer o processo de despojamento de $\mathrm{Mi}$ guel durante os atendimentos.

Apesar de apropriar-se de forma crescente e efetiva dos atendimentos e de demonstrar sentir-se à vontade na presença da psicóloga em decorrência do estabelecimento da uma relação empática e acolhedora, Miguel demonstrou muita dificuldade em expressar verbalmente a experiência com o pai, sendo o atendimento mencionado acima o único momento em que ele citou o ocorrido. Assim, ainda que a experiência do abuso tenha sido o motivo do encaminhamento da família (mãe e criança) para o PAEFI , a criança não verbalizou o episódio, talvez por não demandar externalizar a experiência vivida. Neste aspecto o respeito da psicóloga pelo tempo e pela demanda construída por Miguel, bem como pelas dificuldades ou mesmo indiferença do mesmo diante de algum fato, foram fundamentais para o processo de crescimento pessoal dele.

$\mathrm{O}$ acolhimento à criança possibilitou que ela construísse sua própria demanda, pois também possibilitou uma reiteração simples de suas falas e a conduziu num fluxo contínuo da sua experiência. A oportunidade oferecida à criança de vivenciar e experimentar um espaço livre de julgamento e com condições facilitadoras potencializou a busca por habilidades que favoreceram a própria criança a construir, lidar e até mesmo simbolizar de forma adequada suas demandas pessoais. $\mathrm{O}$ respeito que a profissional de psicologia teve pela capacidade de Miguel em resolver seus próprios problemas possibilitou que ele construísse o que para si realmente representava um problema. Dessa forma, pode-se entender, conforme Fonseca (1998) que atitude de consideração positiva incondicional pela experiência do cliente por parte do terapeuta pode revelar-se 
como favorecedor de um clima de relação passível de propiciar condições ao cliente para uma progressiva reorganização de seu modo de funcionamento.

Assim, em outro dia, Miguel chegou ao atendimento com uma expressão alegre, parecia bem disposto, sentou- se e logo começou a desenhar. Enquanto desenhava Miguel falou que sua irmã não estava mais doente e falou sobre seu pai:

M. [...] eu falei com ele por telefone, minha mãe ligou.

P. Então você falou com seu pai por telefone, porque sua mãe ligou para ele.

M. isso. É ela que liga. [...] eu não ligo, nem vejo ele.

P. Entendi que você conversa com seu pai porque sua mãe liga para ele, pois você não telefona para ele, nem o vê.

M. [...] eu não vou ver ele mais. (expressão de riso)

P. Miguel estou percebendo que você não quer ver o seu pai, neste momento. M. só um dia

A aceitação que a psicóloga teve em relação ao Miguel, a permissividade da situação, a identificação dos sentimentos expressos por ele e a reflexão desses sentimentos o auxiliou a clarificar sua maneira de pensar e contribuiu para que ele desse um passo importante ao encontro de, como postulado por Axline (1947), ajudar a si mesmo. No fragmento acima foi possível inferir que Miguel conseguiu exprimir seu sentimento, de forma simples, uma vez que comunicou à psicóloga o seu desejo de não ver o pai ou de somente ver este pai "um dia", um dia quem sabe quando a experiência do abuso já não tocá-lo mais, como hoje o faz. Foi possível perceber pela fala de Miguel que ele começou a vivenciar a experiência de fazer escolhas, como a escolha de não ver mais o genitor.

Em um dos últimos atendimentos Miguel chegou bem animado, como de costume no período mais avançado do acompanhamento. Ele passou o atendimento brincando e falando dos jogos e brincadeiras realizadas nas férias. Durante o atendimento, Miguel escolheu o que iria fazer, com o que iria brincar e o que e quando falar. Ele demonstrou estar alegre e seguro de suas falas e escolhas. Nesse mesmo dia a genitora relatou que iria viajar com os filhos e que por isso não poderia vir aos próximos atendimentos agendados. 
Ela confirmou a impressão da técnica dizendo que o filho estava mais alegre, falou da relação carinhosa e protetora que ele estava tendo com a irmã.

O acompanhamento foi finalizado no momento em que a violação de direito que levou a família a ser inserida no serviço havia sido cessada e, sobretudo, quando os vínculos familiares haviam sido fortalecidos. A genitora efetivou o encaminhamento do serviço e iniciou um acompanhamento psicológico dela e de Miguel no Centro de Saúde. Além disso, o acompanhamento sócio-assistencial do PAEFI possibilitou à Sra. Sueli livrar-se do seu sentimento de culpa em relação ao acontecido, e a aceitar integralmente o corrido como algo que não pode ser mudado, mas evitado em situações futuras por meio do fortalecimento de sua capacidade de proteção em relação aos filhos. A aquisição, por parte de Sueli, da sua autonomia e da segurança em relação a sua função materna se deu, também, em virtude do crescimento pessoal de Miguel. Ao final dos atendimentos, Sra. Sueli demonstrava se sentir mais segura para cuidar, proteger e educar seus filhos o que conseqüentemente, também, refletia no comportamento de Miguel.

Ainda com relação à criança, no fim do acompanhamento Miguel demonstrou maior autonomia em suas escolhas, mostrando-se uma criança mais segura. Esta mudança de comportamento evidenciou a importância da relação de ajuda psicológica enquanto auxílio para o indivíduo em direção ao seu crescimento pessoal, sem, contudo, que esta ajuda se dê de forma a conduzir o seu comportamento ou tutelar o sujeito. Desse modo, a relação de ajuda estabelecida entre a psicóloga do PAEFI e Miguel se deu de forma efetiva, pois houve uma compreensão por parte daquela de que este é a pessoa responsável pelo seu processo de desenvolvimento psíquico. E que este desenvolvimento pode ser favorecido pela "tendência atualizante" inata do indivíduo, tendência esta que, segundo Rogers e Kinget (1965/1979) "tende a constantemente desenvolver as potencialidades do indivíduo para assegurar sua conservação e seu enriquecimento, levando em conta as possibilidades e limites do meio"(p.41) .

À vista disso, é possível depreender que o espaço de atendimento no PAEFI constitui-se tanto como um espaço de cuidado quanto um espaço de aceitação, receptividade e disponibilidade 
para que o indivíduo modificasse a sua percepção de si, livre de julgamentos e diretividade. Esse processo foi propiciado a partir do momento em que a psicóloga auxiliou Miguel a entrar em contato consigo, a tornar-se seu próprio referencial, iniciando o processo de tendência atualizante e conseqüentemente iniciando o processo de reorganização do self, o que é fundamental para o término de algum possível sofrimento.

Entendemos assim, que os atendimentos a Miguel tiveram um papel importante na evolução de seu processo de crescimento, pois a terapeuta o auxiliou a realizar suas próprias escolhas de maneira congruente, ou seja, integrando da melhor forma possível suas experiências, percepções e sentimentos. Nesse ponto lembramos ainda as premissas rogerianas, pois ao entender que existe na pessoa essa tendência para o crescimento, o terapeuta tem como papel criar um clima favorável interpessoal que promova seu desenvolvimento no indivíduo; e isso só se dá conforme Távora (2001; 2002), quando se estabelece uma relação significativa que promova o verdadeiro encontro.

\section{Considerações finais}

Diante do exposto reitera-se que a finalidade do presente estudo era apresentar a experiência de um profissional de psicologia segundo os pressupostos da ACP. Tal experiência se deu no contexto das políticas públicas de proteção ao indivíduo, e foi relatada por meio do estudo do caso de Miguel, uma criança vítima de abuso sexual.

Cabe enfatizar que apesar de se tratar de um estudo de caso único, algumas inferências são passíveis de serem feitas. Assim, tal estudo evidenciou que trabalhar com crianças em espaços do serviço público pode ser um grande desafio, sobretudo, quando essas crianças são vítimas de algum tipo de violência. A falta de estrutura física adequada, de diretrizes bem estabelecidas e até mesmo de tempo para a sistematização dos atendimentos são alguns dos entraves que compõem os desafios. Além disso, ao psicólogo tem-se o desafio particular de trabalhar com os indivíduos atentando-se ao fato de não despertar nestes indivíduos demandas clínicas que não possam ser tratadas naquele espaço, visto a natureza psicossocial do acompanhamento. 
Todavia apesar dos entraves, ter a compreensão de que talvez aquele espaço, com toda sua precariedade, fosse o único espaço que esta criança poderia ter para experimentar as conseqüências da situação vivida, foi fundamental; uma vez que, apesar das faltas sentidas, o profissional pode propiciar à esta criança uma atmosfera favorável para o seu crescimento, por meio da sua tendência atualizante.

Ademais o profissional de psicologia inserido no serviço público tem o desafio de não ocupar o lugar de detentor de algum conhecimento superior ao conhecimento que a pessoa traz de si. Este é um cuidado especial que o profissional deve ter, uma vez que, muitas vezes a simplicidade e a vulnerabilidade das pessoas atendidas no serviço as levam a colocar o psicólogo em um lugar de saber que acaba o tornando responsável por "solucionar" os problemas trazidos.

Assim, o pressuposto balizador que o psicólogo deve manter é o conhecimento acerca da tendência atualizante do indivíduo. É esta tendência que faz com que o profissional confie genuinamente na capacidade que outro tem de encontrar suas próprias respostas e alternativas para seus conflitos.

Os atendimentos realizados com Miguel demonstraram que mais importante que técnicas, diagnósticos e demandas trazidas por terceiros, é a confiança que o profissional precisa ter na criança. E confiar não quer dizer pronunciar palavras de encorajamento, mas sim confiar a ponto de entregar à criança a decisão de saltar em direção às suas experiências. Confiar genuinamente na criança e na sua tendência atualizante requer manter o silêncio que ela não decidiu quebrar; requer respeitar o ritmo da criança, sem apressá-la ou sugerir caminhos; requer que o profissional esteja ao lado da criança acompanhando-a e não a sua frente guiando-a; requer que o psicólogo compreenda que o momento do atendimento é da criança e de ninguém mais.

Por mais complexa que seja a situação da violência sexual, atender crianças vítimas desse fenômeno e seus familiares requer do profissional um cuidado especial para evitar as atitudes tutelares. Estas atitudes surgem quando o profissional não confia suficientemente nas forças de crescimento do indivíduo. Evitar, sobretudo, atitudes de consolo, de encorajamento e até mesmo de proteção é 
fundamental para que o indivíduo não seja vitimado além do que a própria situação já o fez.

Estar sensível e receptivo aos sentimentos e ao processo experiencial não só do cliente como aos seus próprios é uma "arte" que não pode ser aprendida como se fosse apenas uma técnica. À vista disso, uma das reflexões deixadas a partir do encontro com Miguel refere- se à escuta comprometida e respeitosa. Uma escuta, que para além do objetivo terapêutico, dedique-se a proporcionar ao outro e mais especificamente à criança vítima de qualquer tipo de violência o resgate da sua capacidade de crescimento pessoal e da sua auto- realização. Importante ressaltar que a efetividade da relação de ajuda estabelecida entre psicóloga-criança dependerá, também, além da escuta empática, da disponibilidade da primeira em considerar todas as manifestações da segunda, de modo a estimular sua expressão e valorizar a sua experiência.

Posto isso, os pressupostos da Abordagem Centrada na Pessoa (escuta empática e da consideração positiva incondicional) que fundamentaram a realização do presente estudo de caso, concomitante com a evolução do processo de Miguel e até mesmo de sua genitora, levam a depreender que no atendimento à criança vítima de violência no espaço do PAEFI mostraram-se como uma possibilidade de atuação, de intervenção, na medida em que o profissional pode agir como facilitador, acolhendo as demandas e auxiliando a criança em suas descobertas.

\section{Referências}

ABRAPIA - Associação Brasileira Multiprofissional de Proteção à Infância e à Adolescência. Abuso Sexual: Guia para orientação para profissionais da Saúde. Rio de Janeiro: Autores e Agentes Associados, 1997

AXLINE, V. M. Ludoterapia: a dinâmica interior da criança. Belo Horizonte: Interlivros, 1984 (Original publicado em 1947).

BRASIL. O Ministério do Desenvolvimento Social e combate à fome. Conselho Nacional de Assistência Social. Tipificação Nacional de Serviços Sócio-assistenciais, BRASIL. Resolução n⿳o 109, de 11 de novembro de 2009, aprova a Tipificação Nacional de Serviços Sócio-assistenciais, 2009. Disponível em: http://www.fecam.org.br/arquivosbd/basico/0.681344001273163950_paefi conceito.pdf Acessado em: 10 abr 2014. 
BRIERE J; ELLIOTT D. M. Prevalence and psychological sequel e of self-reported childhood physical and sexual abuse in a general population sample of men and women. Child Abuse \& Neglect n. 27, p. 1205-1222, 2003.

CONSELHO FEDERAL DE PSICOLOGIA Serviço de Proteção Social a Crianças e Adolescentes Vítimas de Violência, Abuso e Exploração Sexual e suas Famílias: referências para a atuação do psicólogo. 1a. ed. Brasília: CFP, 2009. Disponível em: http://site.cfp.org.br/wp-content/uploads/2009/10/CREPOP_Servico_Exploracao_Sexual.pdf. Acessado em 29 abr 2015

CONSELHO REGIONAL DE SERVIÇO SOCIAL; CONSELHO FEDERAL DE PSICOLOGIA. Parâmetros para atuação de assistentes sociais e psicólogos (as) na política de assistência social. Brasília, CFP/CEFESS, 2007. Disponível em: http:// www.cfess.org.br/arquivos/CartilhaFinalCFESSCFPset2007.pdf. Acessado em: 10 fev 2015

FADIMAN, J; FRAGER, R. Teorias da personalidade. São Paulo: Harbra, 1986

FLORENTINO, B.R.B. As possíveis consequências do abuso sexual praticado contra crianças e adolescentes. Fractal: Revista de Psicologia, v. 27, n. 2, p. 139-144, maio-ago. 2015.

FONSECA, A.H.L. As condições facilitadoras básicas como princípios do método fenomenológico existencial: consideração positiva incondicional. In: FONSECA, A.H.L. (Org) Trabalhando o legado de Rogers: sobre os fundamentos fenomenológico existenciais. Macieó: PEDANG, 1998

MATTAR, C.M. Três perspectivas em psicoterapia infantil: existencial, não diretiva e Gestalt-terapia. Contextos Clínicos, v.3, n.2, p.76-87, jul-dez, 2010

ROGERS, C. R. Pode a aprendizagem abranger ideias e sentimentos? In: ROGERS, C. R.; ROSENBERG, R. (Orgs.) A pessoa como centro. São Paulo: EPU, 977. p. 143-161. (Original publicado em 1974).

ROGERS, C. ; KINGE, T, G. Psicoterapia e relações humanas. Belo Horizonte: Interlivros, 1979. (Obra originalmente publicada em 1965).

ROGERS, C. R. O tratamento clínico da criança-problema. São Paulo: Martins Fontes, 1978. (Original publicado em 1939).

ROGERS, C. R. Tornar-se pessoa. 2a ed. Trad. De M. J. C. Ferreira. São Paulo: Martins Fontes, 1987. (Original publicado em 1961).

ROGERS, C. R. Terapia centrada no cliente. Trad. De C. C. Bartalotti. São Paulo: Martins Fontes, 1992. (Original publicado em 1951). 
ROGERS, C. R.. As condições necessárias e suficientes para a mudança terapêutica na personalidade. In: WOOD, J.K; J. R. DOXSEY, J.R.; ASSUMPÇÃO, M.L; . TASSINARI, M. A et al. (Orgs.). Abordagem centrada na pessoa. 4a ed. Vitória: EDUFES, 2008. p. 143-161. (Original publicado em 1957).

SANTOS, G. G.; ALVES, R. S. Violência sexual contra criança e adolescente. Revista Internacional de Direito e Cidadania. São Paulo, v. 01, n. 07, p. 49-58, jul.-set, 2010.

TAVORA, M. T. Treinamento em psicoterapia individual, de grupo e de casal: um guia para supervisores e terapeutas iniciantes. Fortaleza: Programa Editorial Casa de José de Alencar, 2001.

TÁVORA, M. T. Um modelo de supervisão clínica na formação do estudante de psicologia: a experiência da UFC. Psicologia em Estudo, v.7, n.1, p.121-130, 2002.

YIN, R. K. Estudo de caso: planejamento e métodos. Porto Alegre: Bookman, 2001.

Contato do autor:

Juliana Campos - Endereço Profissional: Av. Silva Lobo, 1280, Nova Granada Belo Horizonte, M.G.

email: ju.leila@hotmail.com

Recebido em: 02/02/2016

Aceito em: 20/09/2016 